\title{
Using Information and Communication Technologies in
} Hospital Classrooms: SAVEH Project

\section{Carina S. Gonzalez*}

Department of Systems Engineering and Control and Computer Architecture Universidad de La Laguna 38200, La Laguna, S/C de Tenerife, Spain

E-mail: carina@isaatc.ull.es

\section{Pedro Toledo}

Department of Systems Engineering and Control and Computer Architecture Universidad de La Laguna

38200, La Laguna, S/C de Tenerife, Spain

E-mail: pedro@isaatc.ull.es

\section{Silvia Alayon}

Department of Systems Engineering and Control and Computer Architecture Universidad de La Laguna 38200, La Laguna, S/C de Tenerife, Spain

E-mail: salayon@ull.es

\section{Vanesa Muñoz}

Department of Systems Engineering and Control and Computer Architecture Universidad de La Laguna

38200, La Laguna, S/C de Tenerife, Spain

E-mail:vmunoz@ull.es

\section{Dolores Meneses}

Department of Information Science

Universidad de La Laguna

E-mail: dmeneses@ull.es

*Corresponding author

\begin{abstract}
Children suffering a serious illness, experience enormous changes in their daily lives. Not only does the direct consequences of the disease affect the child, but also the fact of being at a hospital, or at home and not being allowed to go to school. Frequently, connections with classmates, neighbors, and sometimes even some with his relatives are lost. Furthermore, the responsibility of the state, to continue his schooling process is much harder, since different communities (family, school teachers, hospital teachers, medical doctors, psychologists...) have to be coordinated. Last but not least, entertainment and
\end{abstract}


enjoyment should be provided to avoid boredom and to improve their affective state. At the same time, with the development of Information and Communication Technologies, a large number of solutions have arisen that allow people to enhance their communication, education and entertainment possibilities. These technologies seem perfectly suitable to be used to tackle the problems described above. In this article, some of the special necessities of children suffering from a serious illness are pointed out, technologies available to be facilitated are described and some initiatives taking place in Spain mentioned. The SAVEH project will be described in detail.

Keywords: Hospital classrooms; Information and Communication Technology (ICT); Health care system

Biographical notes: Carina S. González got her $\mathrm{PhD}$ (Cum Laude) in Computer Science from the University of La Laguna (ULL), Spain, in 2001. Currently she teaches in the Department of Systems Engineering and Control and Computer Architecture of ULL. Her main focus area in research is the application of AI and multimedia adaptive interfaces in education. She is also director of the Educational Innovation and ICT and the Center of Virtual Learning at ULL, member of EDULAB (Laboratory of Education and New Technologies) and member of IEEE and of the Spanish Chapter of the IEEE Education Society, Association of Human-Computer Interaction of Spain, and Distance Education Net, among others.

Pedro Toledo received the degrees in Computer Science Technical Engineering and Computer Science Engineering from the University of La Laguna (Spain) in 2002 and 2004 respectively. He is a Ph.D. student at the same university since 2004, in the Department of Systems Engineering and Control and Computer Architecture. In addition, he collaborated with the DTAI group of the Computer Science Department of the Katholieke Universiteit Leuven during the year 2008, and with the Information Systems Group of the Computer Science Department of the Technische Universiteit Eindhoven, during 2009 and 2010. His current research interests include Reinforcement Learning, Graph Mining, and Workflow Induction, and Educational Data Mining.

Silvia Alayón received the M.S. degree in Electronic Engineering from the University of La Laguna (Spain) in 1999, and the Ph.D. degree in Computer Science from the same university in 2003. Since 1999, she is teacher in the Department of Systems Engineering and Control and Computer Architecture, University of La Laguna, where she is currently an assistant professor in Systems Engineering and Automation. Her areas of interest include automation, signal processing, image processing, artificial intelligence and neuro-fuzzy systems for medical applications.

Vanesa Muñoz received her MS degree in Computer science in 2001 and her $\mathrm{PhD}$ degree in Computer Science in 2007 from the University of La Laguna. She is professor in the Department of Systems Engineering and Control and Computer Architecture at the University of La Laguna, Canary Islands, Spain. Her current research interests are decision-making, discrete event simulation, intelligent agents, intelligent tutorial systems and computer education.

María Dolores Meneses Fernández has a degree and $\mathrm{PhD}$ in Information Sciences and graduated with a PhD in Geography and History. She is teacher of Technology in Journalism and Communication and in Biomedical and Environmental Technology at the University of La Laguna. She has published numerous research papers on Social Communication and History. Her research focuses on the relationship of journalism to other scientific disciplines and 
technology in the journalistic ethics. One of her lines of communication is specialized in biomedical and biotechnological content broadcast on Spanish media.

\section{Introduction}

A great change in life happens when anyone is diagnosed a serious illness. Not only do the direct consequences of the disease have an impact on the person, it also usually has a negative effect because of the changes in habits and the daily life of the patient. Many serious diseases force people to spend long periods of time combining stays in the hospital and stays at home. Isolation is usually experienced somehow, as a factor which negatively influences the mood and health of the person.

The situation when the patient is a child or a teenager is even more significantly striking. In these periods of life, keeping in touch with family, friends, and classmates is clearly essential for emotional stability. Isolation is the fact that makes the lives of these children much harder apart from the direct consequences of the illness. A complete lack of communication with their environment usually appears for long periods of time. The children usually don't have contact with their friends or relatives during long periods of time in the day, however they feel they need them more frequently than before. The educational process is usually stopped, and the relation with their classmates completely interrupted, with the exception of the closest ones. During the stays either at hospital or at home, entertainment activities are not easily found to be compatible with the medical situation. Apart from the children themselves, around the children there is a large community, with little direct interaction with them, even when their activities should be coordinated to improve the children's situation. (e.g. coordination between teachers and doctors to know about the patient condition, the families and teachers, friends, etc.).

Furthermore, there are educational needs that should be satisfied. Providing the resources to guarantee the correct educational attention of the underage is not only an option but a requirement of the State, based on the Spanish Legislation and International agreements (Spanish Institute of Educational Technologies, n.d.).

Fortunately, for some time, there have been multiple initiatives with the main objective of trying to mitigate the side-effects of the hospitalization, and the periods of stays at home, allowing children at the same time to continue with the schooling process. Many of these initiatives are mainly focused on using ICTs to improve the services held by the institutions. The use of ICT's enables a great number of solutions, with the most outstanding ones described in this article HOPE (Projects of ICT Technologies in Europe, n.d.).

SAVEH is an European project actually being developed by universities, hospitals, and private organizations of Spain and Portugal, trying to deal with the development and integration of ICT tools and electronic contents, in the context described above (see http://saveh.es). The rest of this article is organized as follows. Section 2 describes the most relevant initiatives developed in Spain while Section 3 details the SAVEH project, pointing out the main contributions of the project to the community. Next, in Section 4, a SWOT analysis of the usage of ICT in this context is presented. Finally, the technological proposal developed in SAVEH are discussed and conclusions are presented. 


\section{Related initiatives in Spain}

In Spain, both the health care system and the education system are not directly managed by the central administration. On the contrary, the seventeen regional governments are responsible for it. This is the reason why the situation in hospital classrooms in Spain needs to be analyzed independently in each of the regions. Differences between them are noticeable.

Analyzing each of the regions, the most outstanding ones (which have an associated web portal where they share information) are described below.

- Cantabria: In this region a rather ambitious project of the educational administration is being developed, including the development and use of ICTs. Their web-portal Educantabria is extensive in the information shared with the community. This information targets students, teachers, families, centers, etc. There is a list of the services that have been designed. It includes a catalog of educational resources. Also, there is a list of web services including educational portals, center management systems, services for the evaluation of the quality of education, contact between centers, services for teachers education, etc. They have their own online TV channel, information search services, they provide email to the members of the community, etc.

- Andalucía: The web portal created in Andalucía is called "averroes", and it is where the information and services are centralized. However, it is of special interest in that the materials are developed in relation with hospital classrooms.

- Cataluña: Xtec, is the information web portal of Caluña. It includes detailed information about the protocols to follow when a child needs special educational attention because of an illness.

- Madrid: Similar to the previously mentioned regions, there is a web site where information about educational service is located. It is called Educamadrid. Nevertheless, concerning children suffering illnesses, it is worth mentioning SAED, which is the service for domiciliary educational aid. This service has optimized the administrative process necessary to be completed when a child needs assistance. A whole set of documents are available, naming those responsible to fill in and sign each of them and the institution to which it has to be addressed.

- Navarra: Creena is located in Navarra, as their central information point. Their effort is remarkable in compilation of links to information in both the development of new ICT's for education, as well as about programs for educational aid programs.

- Canarias: In the Canary Islands Medusa has been developed as a service for the educational community for the use of ICT in schools.

Additionally, some interesting Spanish initiatives should be mentioned, because of being specially localized in the innovative use of ICT in education:

- "Educared": It is an initiative of "Fundación Telefónica" for the improvement of the schooling process focused mainly in South American countries. It coordinates a huge variety of initiatives, develops electronic resources, collaborates with specific projects, works as a meeting point for the community, etc. In addition, they are now continuing with "Educalia", initially developed in Cataluña. Educalia, is an educational program developed for children between three and eighteen years old, their families and teachers. Within the program 
multiple initiatives have taken place, including workshops, games, a virtual library, etc.

- "e-Hospital": Is a Project mainly focused on enhancing the potential benefits of learning activities during hospitalization. The main approach involves using computer-assisted learning for people restricted in their mobility and time space availability, while improving their social interaction promoting joint learning activities. The technological framework used in this project is based on dokeos.

- "Mundo de Estrellas": One of the projects was developed by the previously mentioned institutions of Andalucía, and "Hospital Universitario Virgen del Rocío". The project creates a virtual world in which the children may create characters, make their avatars play a script, meet other students characters, etc. Videoconferences are also one of the features allowed while using this framework.

- "Aula en Línea": This is a free application accessible online, created by CajaMadrid with the purpose of promoting online education in the context of healthcare environments. It integrates profiles of students, health care professionals, families, student tutors, friends and teachers. It provides educational and health electronic resources, forums, chats, games, etc.

- "Mercurio": The first educational online TV-channel offered to the educational centers is Mercurio and it has been developed in Extremadura. Each center has the chance to have their own TV-channel in which they may offer their own educational contents. It is considered as well to be a virtual classroom for students. They are also be able to watch classes online, and ask questions to their teachers remotely.

- "Curarte": This Project was started by Universidad de Salamanca and Universidad Complutense de Madrid, with the objective of integrating creativity, games and art in the healing process of children in hospitals. The initiative not only focused on the creation of physical expressions of art, but also, the design of virtual sculptures and video games.

Other significant related experiences in the world of hospital classrooms with children and adolescents are focussed on the use of social ICT and in helping students in the learning process and improve their reintegration into regular studies when they return to school. We cite here some of the most relevant: National Network "Acercándote @1 Mundo" (Argentina), Livewire (Australia), Starbright World (EEUU), Tlalim (Israel), Project Caroline and Christer (Sweeden), "Fundación Educacional Carolina Riquelme" (Chile), Hospital Classrooms (Perú) and Health Program r-Educared (Argentina), among others.

\section{SAVEH Project}

SAVEH is a project, currently under development by institutions in Spain and Portugal: Universidad de La Laguna, Hospital Universitario de Canarias, Universidade dos Açores and Asociación Innovalia. The main objective of the project is the development of a Hospital centered Virtual Aid Educational Service, targeting the community that deals with Hospital Classrooms. The project would identify the main problems and necessities to be covered in the Hospital Classrooms, and would make use of different ICT tools to build a global solution. Despite the fact that educational goals to be achieved by the students are considered important, the main focus is to work on social affective aspects. 
The context in which the project is mainly developed is the Canary Islands. Each of the seventeen Autonomous Communities of Spain has its own health care administration. Within the Canary Islands there are seven Hospital Classrooms and two additional smaller ones.

In each of these classrooms there is one teacher to attend children. Teachers in the classrooms have to call on one by one to the school centers the children they have in their classroom, to coordinate the activities. These is especially important since children usually alternate between short stays at hospital, with stays at home, and stays attending ordinary classes at school. Nevertheless, teachers don't have any special tool, provided by the local government, to communicate with themselves or to share their experiences, other than the phone and e-mail.

At the same time, professionals desire ways of improving their interaction with children. The situation in hospital classrooms are rather different than at school. Each and every one of the children is living with a different situation which requires different kinds of activities to be proposed by the teacher. This makes it much harder to appropriately attend to all children at the same time. Actually, that is not possible at all on a daily basis. Because of these reasons, teachers can only spend a few minutes with each of the children.

\section{ICT for hospitalized children: A SWOT analysis}

In order to diagnose the actual situation of the hospital classroom in the "Hospital Universitario de Canarias" in the context of the SAVEH project a population of ten children, their families, sanitarian, and the social and educational environment has been analyzed. It seems reasonable the development and adaptation of ICT can be applied to tackle the problems of the children. The characteristics of the tools seem to meet some of the needs that appear in their situation. Nevertheless, new technologies will not always be able to mitigate the difficulties in the most appropriate way. For this reason a SWOT analysis is presented, providing a summary of the advantages, disadvantages and limitations of technology (Figure 1).

\section{Strengths}

Social Aspects: As it has been shown, enhancing communications has become one of the most powerful characteristics of ICT. Currently it is assumed that almost every computer, and what is more, every electronic device can be potentially connected to the Internet and to other analogous devices. Most of the tools developed currently are modeled having this in mind (Castells, 1999).

At the same time, it is absolutely clear that a large percentage of the population do access the Internet, on a daily basis, not only because of their work but also during their spare time (Benchmarking Digital Europe, 2010). This use is also extended within the young population who do not notice any handicap in the use of technology.

As a result, social networks have become very popular during the past few years. The community of people connected in these networks becomes bigger every day. Even if the most popular Social Networks target adults, open source Social Network engines are available as well as online services to create your own community. As described, they allow people to stay in contact with each other, share messages, have information of their own profile, update photos and videos, etc. 


\section{SWOT Analysis - ICT in Hospital Schools}

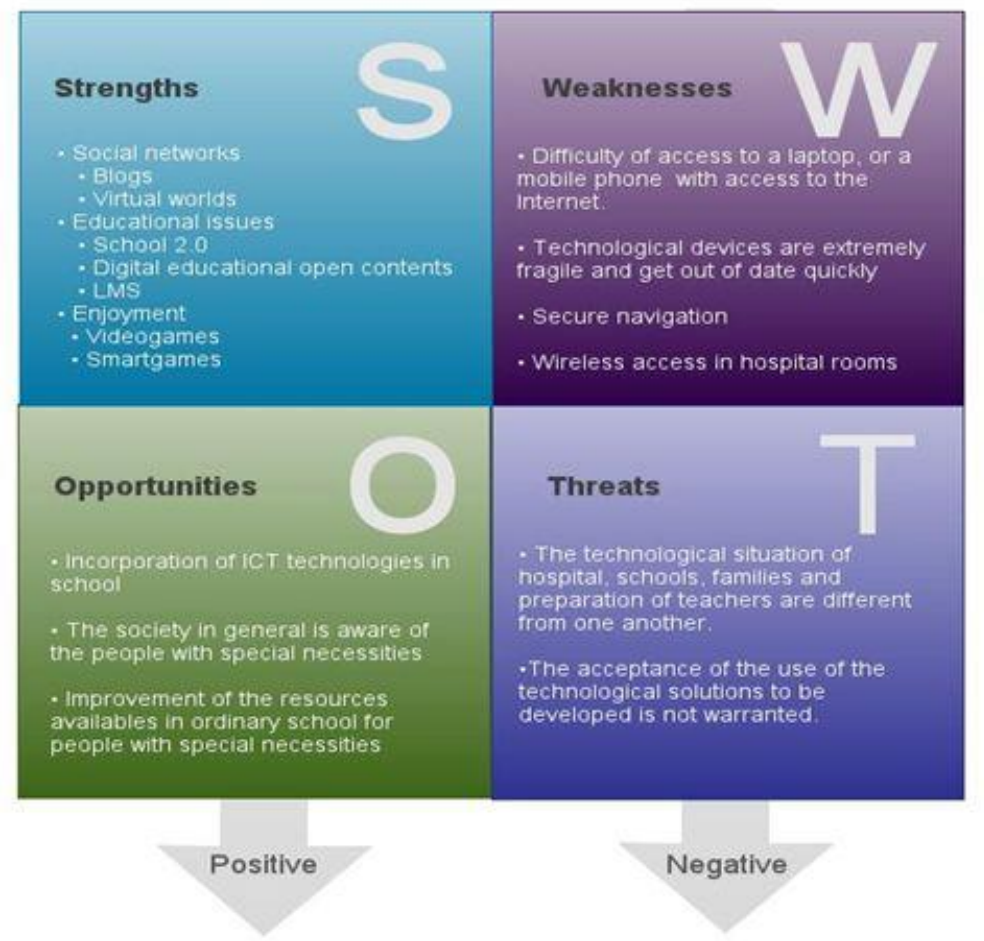

Figure 1. SWOT analysis. Advantages, disadvantages and limitations of technology

Blogs are also a well known tool to share opinions and thoughts, and receive comments from the community. They are able to reduce the sensse of isolation a person may have, since this person feels free to express ideas, not targeting its speech to a physical person but those willing to read it.

Games are also a great way to interact with other people. Games have been developed in which the player has to compete among others to reach a goal, including not only computer players moved by an Artificial Intelligence engine, but real people playing remotely. Furthermore, not only competitive roles can be played out but also cooperative ones. It is frequently found, that in order to achieve the established goals players should form teams, plan a strategy, coordinate themselves and help each other when they find difficulties (BECTA, 2006).

Educational Issues: School 2.0 has come to stay with us. Electronic platforms to aid teachers in their labor are widely used. Teachers can use them as a repository of materials, to order the tasks they want the students to work in, etc. But to coordinate teacher's work when the students are not in the classroom, these tools are even more powerful. They allow logging of the activity of the students, letting them check their routines, preferences, satisfy their doubts even if they work outside the working hours when the teacher is connected. Furthermore, multimedia resources can be linked, and produced, and more specific educational materials assigned to students when special 
needs are detected. These tools seem to be in the line of what it is needed for children that cannot regularly go to school because they are suffering from an illness.

Enjoyment: It is clear that the affective part of the disorders experienced by children at hospital, should be one of the priorities of an educator in a hospital. Children usually get bored, and they have a considerable amount of time to do activities when their illness permits. Unfortunately, a hospital is not the kind of environment where a child can naturally find distractions. Even if they should stay in bed or not, there are not many places where they can go, spaces where they can play, or other children with whom they can freely talk. Nevertheless, video games are usually products that can entertain children during long hours, without necessarily requiring physical activity and contact with others, which can be frequently forbidden for them. At the same time, games can be designed and selected to develop skills in the children at the same time they play, even when they not even able to notice (Gee, 2008). As it was mentioned, smart games can focus on very specific aspects of the mental development of a person, while the player only perceives a challenge, and a goal to be achieved (European Schoolnet, 2009).

\section{Weaknesses}

Unfortunately, the use of technologies by the children presents some difficulties as well (Anonymous, n.d.). Currently, the price of the devices needed to connect to the Internet is relatively low. Nevertheless, some families still cannot afford investing money in them. Despite the government's efforts to provide or subsidize each family with a computer, that it is not enough to be able to guarantee children will have access to a laptop, or a mobile phone with access to The Internet. Additionally, technological devices are extremely fragile and get out of date quickly. This makes it usually impossible for one child to inherit the device from an older brother.

At the same time, the situation when a child has an illness, does not always allow them to use any device at all. Even if it is a mobile or a laptop that can be handled from bed, this can be sometimes discouraged.

Last but not least, no electronic communication technology will be able to substitute completely for the needs of human interaction. Even being able to share video, audio, express our feelings, and have online interaction with other people, there are still major inconveniences that remain unsolved.

\section{Opportunities}

The current social, economical, and technological context may also benefit through the use of technology. It can be observed how society in general is aware of people with special needs even more that it was in the past. Extension and democratization of media has lead to the development of communities which represent minorities able to express themselves reaching the societies through the Internet. Since special needs of children suffering of a serious disease can be pointed out, and expressed to the public, there is a potential demand for the society to cover them.

At the same time, similar (but not the same) approaches are being developed and deployed in ordinary schools in order to improve the resources available, and to increase the effectiveness of the schooling process. While it is not the same situation, and then, not exactly the same goals are being pursued, it is a fact that the incorporation of ICT technologies in school is an advantage that can be exploited in a rather straightforward way. 


\section{Threats}

Finally, there are also some aspects that threaten the development of ICTs and their incorporation in hospital classrooms.

The technological situation, administration and preparation of teachers are different from one another. First of all, the educational administration in Spain is divided into seventeen units, one for each of the Autonomous Communities, detailed in the Constitution. Healthcare Systems and are also administrated by them. This heterogeneous landscape does not help to spread unique technological solutions in all regions, since each region has established its own plan, and tackles problems with different priorities.

Furthermore, each school is autonomous and can decide with their own criteria which could also affect the use and implantation of technologies in its classrooms. In addition, each teacher has his own background education and willingness to the use of ICT.

Because of this, acceptance of the use of the technological solutions to be developed is not guaranteed. The heterogeneous situation includes the families as well. The willingness of each of them to provide or even allow the children to have access to the Internet may be different from case to case. Nevertheless this situation may be softened when the appropriate information is provided, and strict access control and monitoring is implemented in the technological solutions provided.

Finally, it should be included in the discussion that the cooperation between several institutions is needed to coordinate these actions. The approaches should be approved not only by the health care system, but also by the educational administration, and at the same time, people with different roles within these institutions should work together. Pediatricians, social educations, psychologists, teachers, tutors, etc. are some examples of the different roles that should work together.

\section{Proposed Technological Solution}

In order to make the actual situation evolve and improve, once the main problems have been identified, a package of technological solutions is currently being designed to be provided, not only to children in the hospital classrooms, but also to those staying at home, their friends, family, classmates, etc.

Some of the specific tools to integrate in the platform being developed include the following (see Figure 2):

- Educational Platform: This platform allows the coordination of the schooling process for each of the students in the hospital classrooms. The student tutor and the classroom teachers may access the platform to add activities, tasks, have conversations between themselves, coordinate the actions, make an evaluation, etc. The chosen technical solution to support the platform is Moodle (see http://moodle.org). Within moodle, each child has its own "virtual classroom" in which a personal record and profile is built. Teachers from the school and hospital use this tool to coordinate the activities and for tracking the student evolution. Considering the limitations ill children may have, it can provide access to the platform from mobile devices. This allows interaction with children while they stay in bed, or are far from places with any other IT infrastructure, other than a mobile phone. 


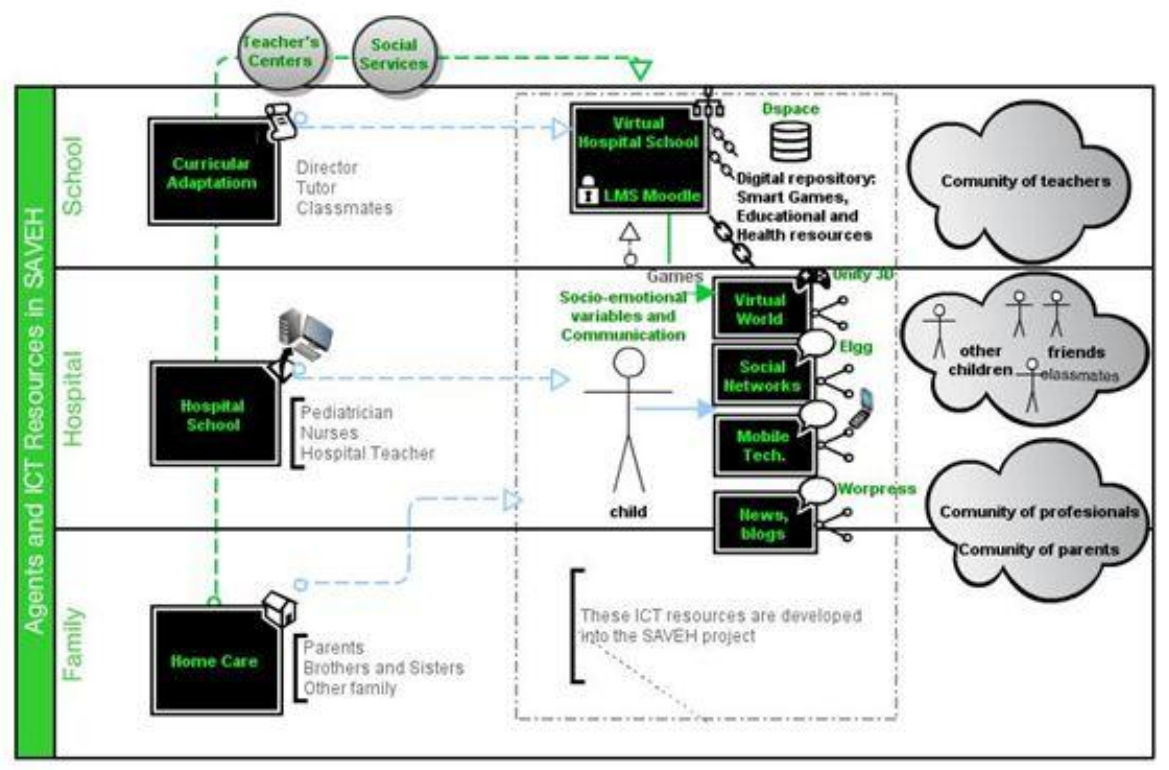

Figure 2. ICT tools and agents integrated in SAVEH's technological proposal

- Virtual World: There would be a virtual world in which students will be able to have a character, with whom they will be identified. This is going to be an environment in which they will have the chance to play, and find some quests that will make them learn, play, enjoy and interact involving a complete set of activities specifically designed. Within this environment children will find as well other characters to interact with, collaborate and compete. The major characters in the virtual world evolve with the behavior of the players, in such a way that the player has the feeling of having an environment tuned to their mood and their personality. The activity of playing is not only a way of distracting the children from their daily life, but a way to make them keep contact with others, feel they have goals to complete and relations to maintain. Technologically, the virtual world is supported by Unity3D (Unity3D, n.d.), creating a fully 3D environment, with animated characters, and engaging scenes.

- Social Networks: Keeping in touch with the environment outside the hospital and their home is essentially important for children. For this reason a Social Network environment will be available. Access to the network will be controlled by teachers, but it will be open to the childrens' relatives, friends, classmates, other children from hospital, etc. In the same way as the virtual educational platform, social networks are accessible from mobile devices. To support this social network, ELGG (ELGG, n.d.) is to be used.

- Smart Games: An exhaustive categorization of the types of known smarts games is being completed. Then their advantages will be analyzed, to tag each of them with the target users they are recommended for. As a result, there will be a large catalog of smart games available, making children get entertained at the same time they develop some specific skills. Teachers may also easily select some of these smart-games specifically for some students, when they consider it specially convenient. The catalog supports all kinds of additional multimedia 
resources, containing related contents such as instructions, warnings, other users' results, etc. The implementation of the repository is obtained with DSPACE (Worldpress), which has been successfully used in large projects.

- Educational and Health resources: Since the teacher of the hospital classroom has to take care of the schooling process of children with a large variety of necessities, there is also a diverse set of resources necessary to attend to the students appropriately. Because of this, a catalog of educational resources is provided, making an effort to make it to be as complete and diverse as possible to tackle every situation. At the same time, since children are spending a lot of time in a hospital, and they have to get used to new vocabulary, objects, health professionals, medical protocols, etc. health resources will be also available, with the intention of making children familiar with the world that is suddenly surrounding them. Again, this multimedia repository will be developed using DSPACE as the base technology.

- Mobile Technologies: Since mobility of patients is usually reduced, to gurantee they can make use of the technologies most of the time, mobile technologies are to be provided. WIFI network is going to be available within the hospital section where the children stay. Netbooks or Smartphones are going to be de selected devices to access the web and all the electronic resources. As mentioned, platforms such as moodle, ELGG, etc. are fully accessible from mobile devices. Thanks to the capabilities of the current mobile devices, it is technologically simpler to give this kind of services. Specific applications are easily developed making use of specific Software Development Kits. In addition, if preferred, HTML can be designed to be served directly to mobile devices just changing the design to fit the reduced size screens of the devices.

- News: The experience shared by all the participants in the community around the project should be globally shared to enrich the knowledge and know-how of other institutions and remote communities. Due to this fact, news pages in the form of blogs are going to be available to the members of the project. Around the platform there is a large community of rather different user profiles. Having news from others initiatives and opinions will be crucial to keep all members involved. Within the Web 2.0 standards, this section is held with Wordpress (WordPress. This facilitates the community to promote information considered interesting, give their opinion regarding others information, share it with third parties, etc.

Finally, sometimes families feel there is a lack of information available about all the procedures they should follow and their child's special condition, to make the institutions consider the special situation of their children. To facilitate this work, the processes that should take place to communicate with all the institutions are being analyzed. As a result of this analysis, clear instructions to follow, official documents, and ways to make contact with official sources of information will be displayed within the project web-site.

\section{Conclusions}

Current developments in IT technologies have enhanced personal ways of communication, coordination, entertainment, etc. of people. Nevertheless some specific parts of the population may take enormous advantages of these possibilities. Clearly children suffering from serious illness constitute an example of people who could benefit from such an advantageous new situation. The needs of this population have been studied, 
pointing out the most relevant ones in this paper. At the same time a SWOT analysis of the implications of the use of new technologies in this case has been described. Finally, the current situation in the Canary Islands has been described, along with details of the specific platform being developed within the SAVEH project.

\section{Acknowledgements}

This project has been funded by the INTERREG program MAC 2007-2013.

\section{References}

1. Anonymous. (n.d.). How european children uses the Internet. Available in: http://ec.europa.eu/information_society/activities/sip/projects/index_en.htm\#childr en_internet.

2. BECTA. (2006). Computer Games in Education: Report. Disponible en: http://partners.becta.org.uk/index.php?section=rh\&rid=13595.

3. Benchmarking Digital Europe. (2010). Benchmarking Digital Europe 2011-2015. Available in: http://ec.europa.eu/information_society/eeurope/i2010/benchmarking/index_en.ht m.

4. Castells, M. (1999). Information Technology, Globalization, and Social Development. United Nations Research Institute for Social Development ( UNRISD) Discussion Paper No. 114.

5. ELGG. (n.d.). Open Source Social Networking Engine. http://elgg.org.

6. EUROPEAN SCHOOLNET. (2009). Videogames in the classroom. Available in: http://games.eun.org/upload/gis-full_report_en.pdf.

7. GEE, J.P. (2008). What Digital Games Have to Teach Us About Learning and Literacy. New York \& Basingstoke: Palgrave Macmillan.

8. Projects of ICT Technologies in Europe. (n.d.). Hospital Organization of Pedagogues of Europe (HOPE). Available in: http://www.hospitalteachers.eu/files/index.php?direction=0\&order=\&directory $=\mathrm{Cu}$ rrent\%20information/Active\%20Projects/3\%20-\%20New\%20Technologies\&.

9. Spanish Institute of Educational Technologies. (n.d.). Normative od hospital classroom by provinces. Available in: http://www.ite.educacion.es/w3/recursos2/atencion_diversidad/05_01b.htm.

10. Unity3D. (n.d.). Game Development Tool. http://unity3d.com/.

11. WordPress. (n.d.). Blogging publishing application. http://wordpress.com. 